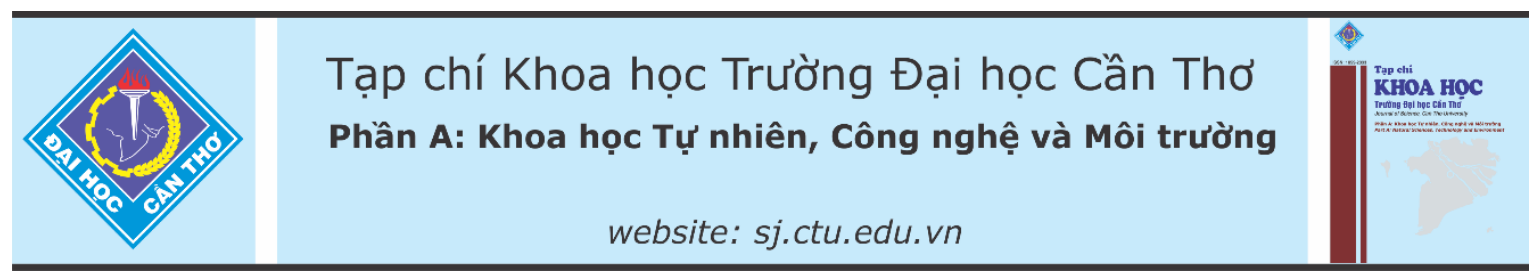

DOI:10.22144/ctu.jvn.2021.115

\title{
NGHIÊN CÚU KHẢ NĂNG HẤP THU NITRATE VÀ PHOSPHATE CỦA VI TẢO ĐƯợC PHÂN LẬP TỬ NƯỚC THẢI SINH HOẠT
}

\author{
Nguyễn Thị Kim Huê ${ }^{1 *}$, Đặng Thanh Thảo ${ }^{2}$, Nguyễn Công Thuận ${ }^{3}$ và Nguyễn Thị Phi Oanh ${ }^{1}$ \\ ${ }^{1}$ Bộ môn Sinh họ, Khoa Khoa học Tự nhiên, Truờng Đại học Cần Tho \\ ${ }^{2}$ Học viên Cao học Khóa 25, Ngành Sinh thái học, Truờng Đại học Cần Tho \\ ${ }^{3}$ Khoa Môi truờng và Tài Nguyên Thiên nhiên, Truờng Đại học Cần Tho \\ *Nguoòi chịu trách nhiệm về bài viết: Nguyễn Thị Kim Huê (email: ntkhue@ctu.edu.vn)
}

\section{Thông tin chung:}

Ngày nhận bài: $16 / 03 / 2021$

Ngày nhận bài sủa: 20/04/2021

Ngày duyệt đăng: 20/08/2021

\section{Title:}

Study on potential for nitrate and phosphate absorbance of microlagae isolated from domestic wastewater

\section{Tù khóa:}

Nitrate, phosphate, phân lạp, vi tảo, xủ lý nước thải

\section{Keywords:}

Isolation, microalgae, nitrate, phosphate, wastewater treatment

\begin{abstract}
Domestic wastewater usually contains a large amount of nitrate and phosphate causing eutrophication and water pollution. Microalgae often accumulate nitrogen and phosphorus from nitrate and orthophosphate to produce their biomass. Therefore, the screening of microalgae that are capable of efficiently absorbing nitrate and phosphate is necessary for initial wastewater treatment. This study investigated the ability to absorb nitrate and phosphate of 6 microalgal strains isolated from domestic wastewater. The results showed that two microalgae strains of phylum Chlorophyta, Chlorella sp.1 and Chlorella sp.2, can remove nitrate and phosphate in the experimental scale with absorption efficiency of $>90 \%$ and $88 \%$, respectively. The result of this study suggests that these two Chlorella sp.1 and sp. 2 can be used as potential agents for management of nitrate and phosphate in domestic wastewater in the upcoming experiments.
\end{abstract}

\section{TÓM TẮT}

Nuớc thải sinh hoạt thuoòng chứa mọt lượng lớn nitrate và phosphate có thể gây ra hiện tương phú duõ̃ng và ô nhiếm môi trường nước. Vi tảo thường tích lũy nitrogen và phosphorus dưới dạng nitrate và phosphate để tạo sinh khối cho chúng. Do vậy, việc chọn ra dòng tảo có khả năng hấp thu hiệu quả nitrate và phosphate là cần thiết để làm co sở cho các nghiên cứu về xử lý nước thải. Nghiên cưu được thực hiện nhằm khảo sát khả năng hấp thu nitrate và phosphate của 6 dòng vi tảo được phân lập tù nguồn nước thải sinh hoạt. Trong 6 dòng tảo được phân lậ, 2 dòng vi tảo là Chlorella sp.1 và Chlorella sp. 2 có hiệu suất hấp thu trên $90 \%$ nitrate và $88 \%$ phosphate đã được tuyển chọn. Hai dòng tảo tiềm năng này được tiếp tuc nghiên cứu xư lý nitrate và phosphate trong nước thải sinh hoạt ở các thí nghiệm tiếp theo.

\section{GIỚI THIỆ}

Cùng với sự biến đổi khí hậu và sự nóng lên toàn cầu, vấn đề ô nhiễm từ nước thải sinh hoạt đã và đang là mối lo hàng đầu của nước ta nói riêng và trên thế giới nói chung. Nước thải sinh hoạt đô thị thường chứa các lượng lớn nitrate $\left(\mathrm{NO}_{3}^{-}\right)$, phosphate $\left(\mathrm{PO}_{4}{ }^{3-}\right)$, ammonia $\left(\mathrm{NH}_{3}\right)$, rác hữu cơ và các vi sinh 
vật gây bệnh như vi khuẩn, virus và các loài giun ký sinh. Nước thải này được đổ vào các sông, kênh, rạch hàng năm do tốc độ đô thị hoá gia tăng. Điều này đã và đang dẫn đến tình trạng ô nhiễm và gây phú dưỡng hoá nguồn nước mặt ở mức nghiêm trọng. Nhiều biện pháp xử lý nước thải đã được áp dụng như: phương pháp xử lý cơ học, hóa học, hóa lý; phương pháp xử lý sinh học bằng vi khuẩn. Tuy nhiên, gần đây tình trạng ô nhiễm nguồn nước vẫn không ngừng tăng lên do các phương pháp xử lý trên chưa có thể loại bỏ triệt để, lượng lớn nitrate, phosphate và ammonia tồn đọng trong nước thải, sau đó các chất này theo các tuyến cống xả trực tiếp ra môi trường. Chính vì thế, việc nghiên cứu để tìm ra biện pháp thích hợp và có khả năng xử lý triệt để các nguồn nitrate, phosphate và ammonia, góp phần xử lý nước thải sinh hoạt đô thị là vô cùng cấp thiết.

Vi tảo là nhóm vi sinh vật đơn bào hay đa bào kích thước hiển vi có khả năng quang hợp như nhóm thực vật ở cạn. Chúng có khả năng chuyển hóa năng lượng ánh sáng mặt trời thành nguồn năng lượng hữu cơ để tăng trưởng và phát triển, đồng thời sản sinh ra lượng lớn oxy cho khí quyển. Vi tảo có giá trị dinh dưỡng và hàm lượng protein cao, một số chứa các chất béo và vitamin thiết yếu mà thực vật thông thường không có. Đặc biệt, vi tảo tăng trưởng và phát triển nhanh trong nước thải do chúng có khả năng sử dụng các chất dinh dưỡng vô cơ như nitrate, phosphate, một số kim loại nặng để chuyển thành sinh khối cho chúng (Yang et al., 2017; Oyebamiji et al., 2019).

Ở Việt Nam, các công bố về khả năng xử lý nitrate và phosphate của vi tảo từ nước thải sinh hoạt rất ít. Các nghiên cứu chủ yếu tập trung vào khả năng xử lý nitrate và phosphate từ nước thải của một số loài thực vật như trầu bà, sen, súng (Nguyễn Thị Kim Ngân \& Phạm Thị Mỹ Trâm, 2017), và bèo tai chuột (Nguyễn Minh Trí và Trần Thị Bích Ngọc, 2015)... Trần Chấn Bắc và ctv. (2015) đã chứng minh khả năng sử dụng các chất dinh dưỡng đạm và lân của vi tảo Chlorella $\mathrm{sp}$. từ nước thải của ao nuôi cá tra để tạo sinh khối cho chúng.

Trên thế giới, việc nuôi cấy tảo để xử lý nitrate và phosphate tuy là một ứng dụng không mới nhưng vẫn đang nhận rất nhiều sự quan tâm và ngày càng được nghiên cứu rộng rãi. Điển hình là tảo lục đơn bào Chlorella vulgaris có khả năng loại $50 \%$ lượng nitrogen sau 48 giờ, làm tăng tổng sinh khối của tảo này lên đáng kể (Kim et al., 2010). Một nghiên cứu khác cho thấy tảo lục đơn bào Scenedesmus obliquus có khả năng sử dụng $155 \mathrm{mg}$ nitrogen tổng số và 4 $\mathrm{mg}$ phosphorus tổng số từ nước thải chăn nuôi heo để tạo ra $1 \mathrm{~g}$ trọng lượng khô của tảo, giúp tăng sản lượng lipid $0,13 \mathrm{mg} / \mathrm{L}$ sinh khối tảo (Ji et al., 2013). Ahmad et al. (2012) đã chứng minh hỗn hợp tảo có khả năng xử lý $97 \%$ nitrate, $93 \%$ phosphate, $34 \%$ sulphate và $41 \%$ chloride từ nguồn nước thải đô thị. Theo McGaughy et al. (2019), Chlorella sp. có thể giúp loại bỏ $99 \%$ ammonia từ nước thải.

Mặc dù nhiều loài tảo được biết có khả năng xử lý nitrate và phosphate, nhưng hiệu quả xử lý phụ thuộc vào từng dòng tảo. Có những dòng tảo thích nghi và hấp thu tốt cả nitrate và phosphate, có những dòng chỉ hấp thu tốt nitrate mà không hấp thu phosphate và ngược lại. Do đó, đề tài này tập trung nghiên cứu khả năng hấp thu nitrate và phosphate của các dòng tảo được phân lập từ nước thải sinh hoạt, từ đó tìm ra dòng tảo hấp thu nitrate và phosphate tốt nhất trong điều kiện phòng thí nghiệm. Kết quả của đề tài sẽ làm cơ sở cho các nghiên cứu xử lý nitrate và phosphate trong các nguồn nước thải.

\section{PHƯƠNG PHÁP NGHIÊN CÚU}

\subsection{Thu mẫu nước thải}

Mẫu nước thải sinh hoạt được thu vào buổi sáng tại 3 địa điểm trên địa bàn quận Ninh Kiều, thành phố Cần Thơ đầu nguồn và cuối nguồn của kênh Mạc Thiên Tích, rạch Tham Tướng và trước cổng Khoa Khoa học Tự Nhiên, Trường Đại học Cần Thơ. Tại mỗi điểm ở đầu và cuối nguồn, khoảng $2 \mathrm{~L}$ nước mặt được thu bằng lưới phiêu sinh thực vật với kích thước lỗ $25 \mu \mathrm{m}$. Tại các điểm thu mẫu, nhiệt độ và $\mathrm{pH}$ được đo bằng máy $\mathrm{pH}$ HM-3IP, $\mathrm{DO}$ (oxy hòa $\tan$ - dissolved oxygen) được đo bằng máy DO-3IP, và TDS (tổng chất rắn hòa tan - total dissolved solids) bằng máy $\mathrm{EC} \mathrm{Mi306.}$

Nước thải được mang ngay về phòng thí nghiệm và được lọc qua giấy lọc có kích thước lỗ $3-7 \mu \mathrm{m}$. Sau đó, rửa miếng giấy lọc và thu phần nước đã rửa để phân lập vi tảo trên môi trường WC (Wight's Cryptophytes) (Guillard \& Lorenzen, 1972).

\subsection{Phân lập và định danh các dòng vi tảo thu từ nước thải sinh hoạt}

\subsubsection{Phân lập vi tảo trên môi truờng $W C$ đặc}

Trong tủ cấy vô trùng, nhỏ 1 giọt nước đã thu được khi rửa giấy lọc lên môi trường WC đặc. Dùng que cấy đã khử trùng trải giọt nước có chứa các tế bào tảo trên bề mặt thạch thành nhiều đường zic-zac để phân tán các dòng tảo.

Sau khi cấy, các đĩa thạch được đặt trong phòng nuôi cấy tảo với nhiệt độ là $22^{\circ} \mathrm{C}$ và chu kỳ sáng: tối là 12:12 giờ. Sau khoảng $3-4$ ngày, trên mặt đĩa 
thạch xuất hiện các khuẩn lạc màu xanh lục. Sau 1 tuần, chọn từng khuẩn lạc riêng biệt để cấy chuyển sang môi trường đặc mới bằng phương pháp cấy ria để tách ròng từng dòng vi tảo. Quá trình cấy ria này được lặp lại vài lần cho đến khi các khuẩn lạc trên mỗi dĩa cấy có hình dạng đồng nhất.

\subsubsection{Kiểm tra khả năng phát triển và độ thuần của các dòng vi tảo trong môi truờng $W C$ lỏng}

Kết thúc quá trình phân lập tảo bằng phương pháp cấy ria trên môi trường đặc, các dĩa có khuẩn lạc đồng nhất được chọn và nuôi trong môi trường lỏng để xác định sự phát triển tạo sinh khối của vi tảo. Trong tủ cấy vô trùng, 1 khuẩn lạc của mỗi dĩa được cấy vào $50 \mathrm{~mL}$ môi trường lỏng trong bình thủy tinh $100 \mathrm{~mL}$. Bình chứa tảo được đặt trên máy khuấy có sục khí ở điều kiện nhiệt độ phòng $22^{\circ} \mathrm{C}$ với chu kỳ sáng:tối là 12:12 giờ. Sinh khối tảo sau 10 ngày nuôi cấy được ghi nhận bằng cách đo giá trị OD của ở bước sóng $650 \mathrm{~nm}$.

\subsubsection{Nhận diện vi tảo hiện diện trong mối bình nuôi cấy}

Các dòng tảo sau khi đã cấy chuyển trong môi trường lỏng được quan sát dưới kính hiển vi để kiểm tra độ thuần và ghi nhận các đặc điểm hình thái ở độ phóng đại 1000 lần làm cơ sở cho việc định danh dựa vào các tài liệu của Bourrelly and Heim (1966), Phạm Hoàng Hộ (1969) và Nguyễn Văn Tuyên (2003).

\subsection{Xây dựng đường chuẩn nitrate và phosphate}

Nồng độ nitrate và phosphate của mẫu nước thải, mẫu thí nghiệm và chất chuẩn được xác định dựa vào bộ Kit Sera (Đức). Chất chuẩn được sử dụng để xây dựng đường chuẩn là $\mathrm{KNO}_{3} 1000 \mathrm{mg} / \mathrm{L}$ ( 8 nồng độ từ 0 đến $200 \mathrm{mg} / \mathrm{L}$ ) và $\mathrm{KH}_{2} \mathrm{PO}_{4} \mathrm{mg} / \mathrm{L}$ (12 nồng độ từ 0 đến $9 \mathrm{mg} / \mathrm{L}$ ). Mỗi nồng độ được lặp lại 3 lần. Mỗi nồng độ được chuẩn bị $10 \mathrm{~mL}$ trong ống nghiệm $10 \mathrm{~mL}$ có nắp đậy. Các ống nghiệm chứa nitrate chuẩn được pha loãng 5 lần và không pha loãng đối với phosphate chuẩn sau khi đã thử bằng bộ kit Sera. Các nồng độ khác nhau của nitrate chuẩn cho màu từ vàng đến đỏ đậm. Các nồng độ khác nhau của phosphate cho màu từ không màu, xanh nhạt đến xanh dương đậm. Mật độ quang OD (optical density) của nitrate và phosphate lần lượt được đo ở bước sóng $430 \mathrm{~nm}$ và $750 \mathrm{~nm}$ bằng máy đo quang phổ SoftMax Pro 7 Software.

\subsection{Khảo sát khả năng hấp thu nitrate và phosphate của các dòng tảo phân lập}

Các dòng tảo thuần có khả năng phát triển tốt trong môi trường $\mathrm{WC}$ lỏng được khảo sát khả năng hấp thu nitrate và phosphate trong điều kiện phòng thí nghiệm. Thí nghiệm được bố trí theo kiểu hoàn toàn ngẫu nhiên 1 nhân tố (các dòng tảo) với số nghiệm thức là số dòng tảo. Thí nghiệm được lặp lại 3 lần.

Các dòng vi tảo sau khi nuôi cấy 8 ngày được đo mật độ quang $\mathrm{OD}$ ở bước sóng $650 \mathrm{~nm}$ và điều chỉnh $\mathrm{OD}$ bằng nhau ở các dòng vi tảo trước khi tiến hành thí nghiệm.

Mỗi lọ thí nghiệm được chuẩn bị như sau: $20 \mathrm{~mL}$ vi tảo được cho vào lọ thủy tinh thể tích $100 \mathrm{~mL}$, sau đó bổ sung $80 \mathrm{~mL}$ môi trường $\mathrm{WC}$ có chứa 62,01 $\mathrm{mg} / \mathrm{L}$ nitrate (từ muối $\mathrm{NaNO}_{3}$ ) và $4,8 \mathrm{mg} / \mathrm{L}$ phosphate (từ muối $\mathrm{K}_{2} \mathrm{HPO}_{4}$ ). Như vậy, trong 100 $\mathrm{mL}$ môi trường, nồng độ nitrate và phosphate ban đầu được sử dụng lần lượt là $49,61 \mathrm{mg} / \mathrm{L}$ và 3,848 $\mathrm{mg} / \mathrm{L}$. OD ban đầu của từng dòng tảo trong mỗi lọ thí nghiệm là khoảng $0,075 \pm 0,005$.

Các lọ thí nghiệm được sục khí và được đặt ở điều kiện nhiệt độ $22^{\circ} \mathrm{C}$, chế độ sáng:tối là $12: 12$ giờ, và cường độ ánh sáng là 3000 lux. Các chỉ tiêu theo dõi được ghi nhận sau 2 tuần nuôi cấy, gồm: (1) sinh khối tảo được xác định thông qua việc đo OD của từng dòng vi tảo và (2) nồng độ nitrate và phosphate còn lại được xác định dựa trên đường chuẩn đã được xây dựng ở mục 2.3 .

Hiệu suất hấp thu nitrate và phosphate được tính theo công thức như sau:

$$
\mathrm{HS} \%=100-\frac{\text { Nồng độ nitrate hoặc phosphate còn lại x } 100}{\text { Nồng độ nitrate hoặc phosphate ban đầu }}
$$

\subsection{Xử lý số liệu}

Gía trị $\mathrm{OD}$, nồng độ và hiệu suất hấp thu nitrate/phosphate của tảo được xử lý thống kê bằng phần mềm Minitab version 16 . So sánh các cặp giá trị trung bình $\mathrm{OD}$ vi tảo, nồng độ/hiệu suất hấp thu nitrate/phosphate dựa vào kiểm định Tukey.

\section{KẾT QUẢ VÀ THẢO LUẬN}

\subsection{Phân lập và định danh các dòng vi tảo thu từ nước thải sinh hoạt}

Mười hai dòng vi tảo xuất hiện trên môi trường WC đặc đã được phân lập, trong đó 6 dòng phát triển tốt trên môi trường WC lỏng (Hình 2). Theo Richmon (2004), phương pháp cấy ria không chỉ thích hợp cho việc phân lập vi khuẩn đơn dòng, mà còn có hiệu quả trong việc phân lập tảo đơn dòng. 
Qua việc kiểm tra trên kính hiển vi, các dòng tảo được phân lập đều đạt độ thuần và không lẫn các dòng vi tảo khác (Hình 1).

Kết quả ở Bảng 1 cho thấy 12 đơn dòng vi tảo hiện diện ở các địa điểm thu mẫu khác nhau đã được phân lập và định danh. Trong đó, 11 dòng vi tảo thuộc ngành tảo lục (Chlorophyta) và 1 dòng
Arthrospira sp. thuộc ngành Tảo lam (Cyanophyta). Các dòng tảo này hiện diện trong nước thải có điều kiện $\mathrm{pH} 7$, nhiệt độ dao động từ $27-33^{\circ} \mathrm{C}$, lượng oxy hòa tan $1,2-3,8 \mathrm{mg} / \mathrm{L}$, và tổng chất rắn hòa tan đạt $102-207$ mg/L. Theo Nguyễn Lân Dũng (2006), các yếu tố môi trường này đều thích hợp cho sự tồn tại và phát triển của hầu hết các dòng vi tảo.

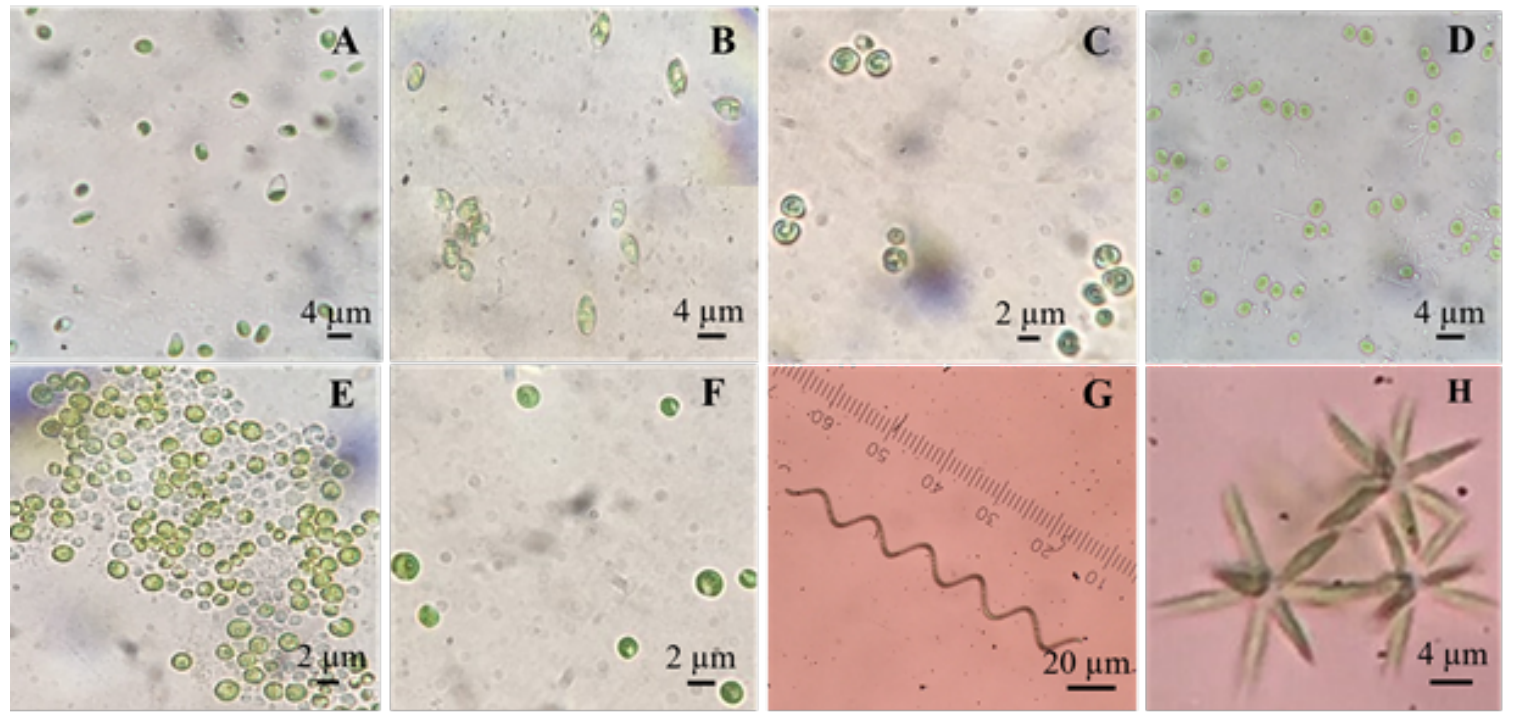

Hình 1. Một số dòng tảo đại diện đã được phân lập từ nước thải sinh hoạt

A: Chlamydomonas sp., B: Scenedesmus obliquus, C: Chlorella sp.1, D: Chlorella sp.2, E: Chlorella sp.3, F: Chlorella sp.4, G: Arthrospira sp., H: Actinastrum sp.

Bảng 1. Mười hai dòng vi tảo được phân lập và một số chỉ số nước thải sinh hoạt tại 3 địa điểm thu mẫu

\begin{tabular}{|c|c|c|c|c|c|}
\hline Địa điểm & Vi tảo & Nhiệt độ $\left({ }^{\circ} \mathrm{C}\right)$ & pH & DO (mg/L) & TDS (mg/L) \\
\hline $\begin{array}{l}\text { Đầu nguồn } \\
\text { MTT }\end{array}$ & $\begin{array}{l}\text { Chlamydomonas sp. } \\
\text { Scenedesmus sp. } 1\end{array}$ & $29,9 \pm 0,28$ & $7,18 \pm 0,01$ & $1,27 \pm 0,04$ & $144 \pm 8,49$ \\
\hline $\begin{array}{l}\text { Cuối nguồn } \\
\text { MTT }\end{array}$ & $\begin{array}{l}\text { Chlorella } \mathrm{sp} .1 \\
\text { Actinastrum } \mathrm{sp} . \\
\text { Pediastrum sp. }\end{array}$ & $33,5 \pm 0,42$ & $7,32 \pm 0,13$ & $1,75 \pm 0,06$ & $102 \pm 6,36$ \\
\hline Đầu nguồn TT & Chlorella sp. 2 & $33,8 \pm 0,49$ & $7,23 \pm 0,08$ & $1,30 \pm 2,11$ & $112 \pm 2,83$ \\
\hline $\begin{array}{l}\text { Cuối nguồn } \\
\text { TT }\end{array}$ & $\begin{array}{l}\text { Scenedesmus obliquus } \\
\text { Bracteacoccus } \mathrm{sp} \text {. }\end{array}$ & $30,3 \pm 0,57$ & $7,2 \pm 0,14$ & $1,42 \pm 0,1$ & $109 \pm 4,95$ \\
\hline $\begin{array}{l}\text { Đầu nguồn } \\
\text { KHTN }\end{array}$ & $\begin{array}{l}\text { Chlorella sp. } 3 \\
\text { Scenedesmus sp. } 2 \\
\text { Arthrospira sp. }\end{array}$ & $27,5 \pm 0,64$ & $7,14 \pm 0,25$ & $1,39 \pm 0,12$ & $207 \pm 3,54$ \\
\hline $\begin{array}{l}\text { Cuối nguồn } \\
\text { KHTN }\end{array}$ & $\begin{array}{l}\text { Chlorella } \mathrm{sp.} 4 \\
\text { Arthrospira sp. }\end{array}$ & $27,9 \pm 0,35$ & $7,21 \pm 0,21$ & $3,79 \pm 0,16$ & $155 \pm 2,12$ \\
\hline
\end{tabular}

MTT: Mạc Thiên Tích, TT: rạch Tham Tưóng, KHTN: rạch phía truóc Khoa Khoa học Tụ nhiên

Hình 2 cho thấy khi chuyển từ môi trường $\mathrm{WC}$ đặc sang lỏng, chỉ có 6/12 dòng vi tảo phát triển tốt trong môi trường $\mathrm{WC}$ lỏng sau 10 ngày nuôi cấy. Giá trị $\mathrm{OD}_{650 \mathrm{~nm}}$ của các dòng tảo Chlamydomonas sp., 4 dòng Chlorella ssp. và Scenedesmus obliquus cao, khác biệt có ý nghĩa thống kê so với 6 dòng tảo còn lại $(\mathrm{p}<0,001)$. Điều này phù hợp với nhận định của Guillard and Lorenzen (1972) rằng mặc dù thành phần dinh dưỡng trong môi trường $\mathrm{WC}$ thích hợp cho việc nuôi cấy hầu hết các dòng vi tảo thuộc ngành Tảo lục, nhưng từng dòng khác nhau thì sẽ phát triển với mật số khác nhau trên cùng một môi 
trường. Bên cạnh đó, một kết quả hoàn toàn phù hợp là tảo lam Arthrospira sp. phát triển kém trên các môi trường dinh dưỡng khác trừ môi trường chọn lọc thích hợp (môi trường Zarrouk) dành riêng cho dòng tảo lam này (Dineshkumar et al., 2016). Do đó, 6 dòng vi tảo phát triển tốt nhất này được chọn để khảo sát khả năng hấp thu nitrate và phosphate trong môi trường WC.

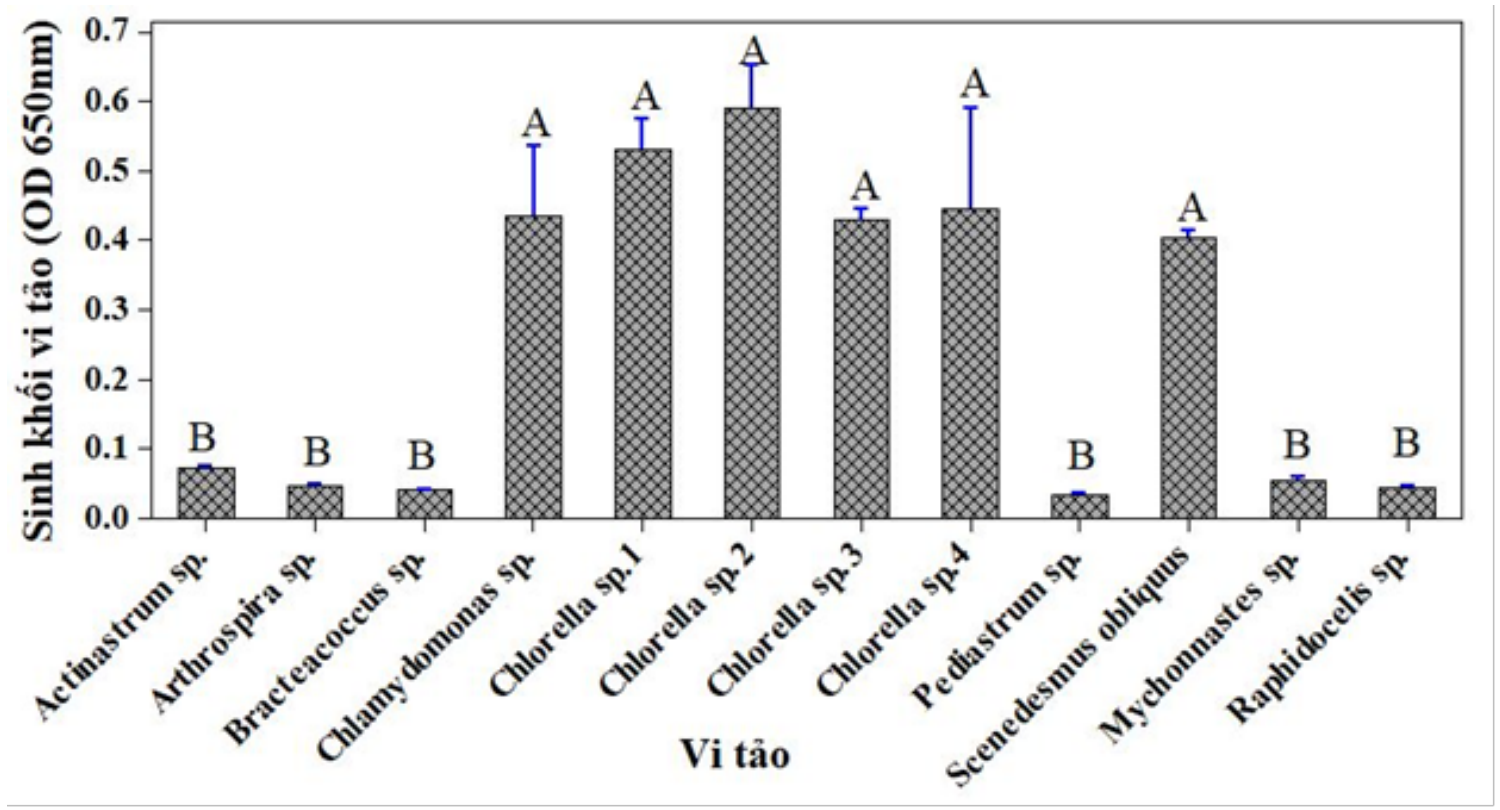

Hình 2. Sinh khối 12 dòng vi tảo khi được nuôi cấy trong môi trường WC

Các ký tụ trên các cột giống nhau thể hiện hàm luợng nitrate trung bình khác biệt không ý nghĩa thống kê. Các thanh trên đầu cột là thanh sai sồ chuẩn.

\subsection{Kết quả xây dựng đường chuẩn}

Việc xác định nồng độ nitrate và phosphate dựa vào phương pháp so màu sử dụng bộ kit Sera của Đức. Bộ kit này có thể sử dụng hiệu quả thông qua việc đo gía trị $\mathrm{OD}$ của các dung dịch chuẩn sau phản ứng tạo màu giữa nitrate hoặc phosphate với các thuốc thử trong bộ kit. Từ đó, đề tài đã xây dựng một quy trình định lượng nitrate/phosphate đơn giản và tiết kiệm thời gian so với phương pháp truyền thống theo tiêu chuẩn Việt Nam (TCVN 6180-1996 cho nitrate và TCVN 6202-2008 cho phosphate).

Nồng độ nitrate và phosphate chuẩn được sử dụng để xây dựng đường chuẩn lần lượt từ 0 đến 200 $\mathrm{mg} / \mathrm{L}$ và từ 0 đến $9 \mathrm{mg} / \mathrm{L}$. Các dãy nồng độ này được chọn chủ yếu dựa vào nồng độ nitrate và phosphate tổng hiện diện trong nước thải sinh hoạt được ghi nhận bởi Lê Hoàng Việt (2003). Đối với dung dịch chứa nitrate, phức chất sau phản ứng có màu từ vàng nhạt (đối với nồng độ nitrate $0 \mathrm{mg} / \mathrm{L}$ ) đến vàng đậm, cam nhạt, cam đậm, đến đỏ tương ứng với nồng độ nitrate trong mẫu từ thấp đến cao. Đối với dung dịch chứa phosphate, phức chất sau phản ứng có màu từ không xanh (đối với nồng độ phosphate $0 \mathrm{mg} / \mathrm{L}$ ) đến xanh dương nhạt, đậm và rất đậm. Ở bước sóng 430 $\mathrm{nm}$ và $750 \mathrm{~nm}$ đối với nitrate và phosphate cho kết quả $\mathrm{OD}$ cao nhất và tăng tuyến tính theo nồng độ tăng dần của nitrate và phosphate. Kết quả ở Hình 3 và 4 cho thấy mối tương quan hồi quy tuyến tính chặt chẽ giữa giá trị OD và nồng độ nitrate/ phosphate chuẩn $\left(\mathrm{R}^{2}>99 \%\right)$. Do đó, phương trình đường chuẩn nitrate/phosphate được đề nghị sử dụng để định lượng nitrate/phosphate dựa vào giá trị OD đo được ở các mẫu thí nghiệm. 


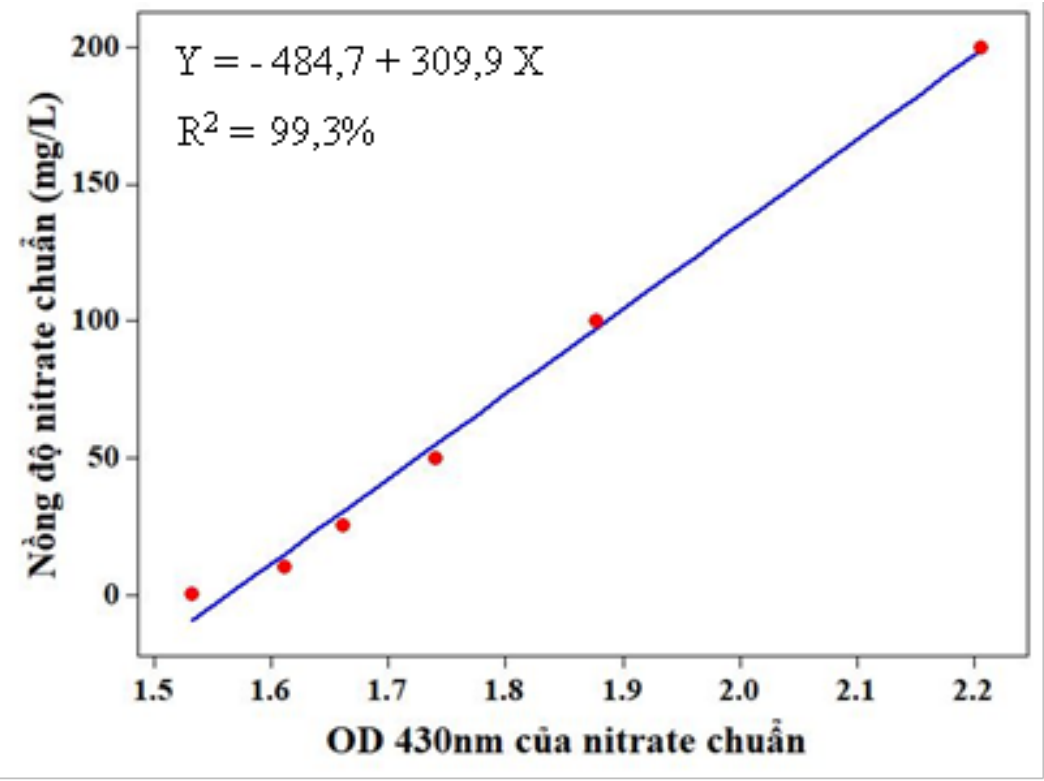

Hình 3. Phương trình đường chuẩn thể hiện mối tương quan tuyến tính giữa OD và nồng độ nitrate

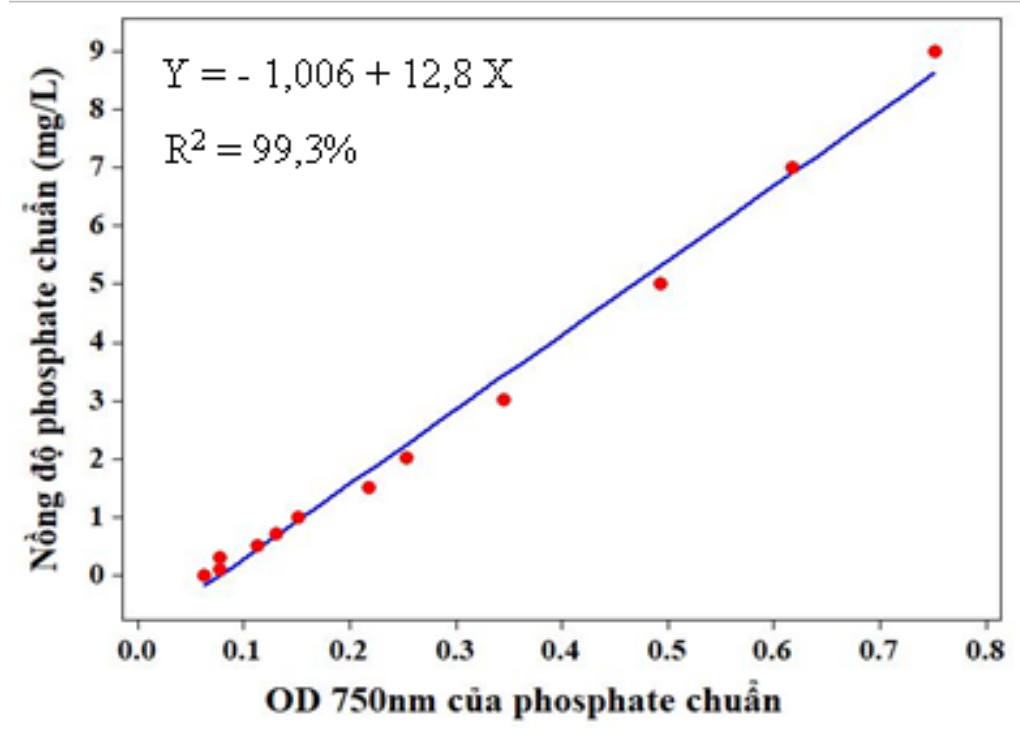

Hình 4. Phương trình đường chuẩn cho mối tương quan tuyến tính giữa $\mathrm{OD}$ và nồng độ phosphate

\subsection{Khả năng hấp thu nitrate và phosphate của các dòng vi tảo đã phân lập}

Thí nghiệm nhằm mục đích tuyển chọn dòng vi tảo bản địa phân lập từ nguồn nước thải có hiệu quả hấp thu nitrate và phosphate tốt nhất. Kết quả nghiên cứu cho thấy hàm lượng nitrate còn lại trong môi trường nuôi cấy các dòng vi tảo đều thấp hơn so với nồng độ nitrate ban đầu (Hình 5). Trong đó, dòng vi tảo hấp thu nitrate tốt nhất là Chlorella $\mathrm{sp} .1$ và $\mathrm{sp} .2$ với hàm lượng nitrate thấp nhất, khác biệt có ý nghĩa thống kê so với các dòng vi tảo còn lại, trừ Chlorella sp.3 (khác biệt không có ý nghĩa thống kê). Mặc dù cùng một giống Chlorella, nhưng Chlorella sp.4 hấp thu không hiệu quả lượng nitrate trong môi trường, nồng độ nitrate còn lại khá cao và khác biệt không ý nghĩa so với nồng độ nitrate ban đầu và so với 2 dòng còn lại là Chlamydomonas sp. và $S$. obliquus. Các kết quả này chứng tỏ nitrogen là một trong các yếu tố dinh dưỡng cần thiết cho sự tăng trưởng và phát triển của tảo. Hầu hết các loài tảo đều có thể hấp thu nitrogen dưới dạng $\mathrm{NO}_{3}{ }^{-}$trên màng tế bào (Graham, 2000). Tảo sử dụng nitrogen để biến dưỡng tạo amino acid, acid nucleic, chlorophyll và 
các hợp chất hữu cơ khác chứa nitơ. Tuy nhiên, do nitơ chiếm $1-10 \%$ trọng lượng khô của tế bào tảo và không giống nhau ở các loài (Đặng Đình Kim,
1999) nên hiệu quả hấp thu nitrate phụ thuộc vào từng loài tảo (Taziki et al., 2015).

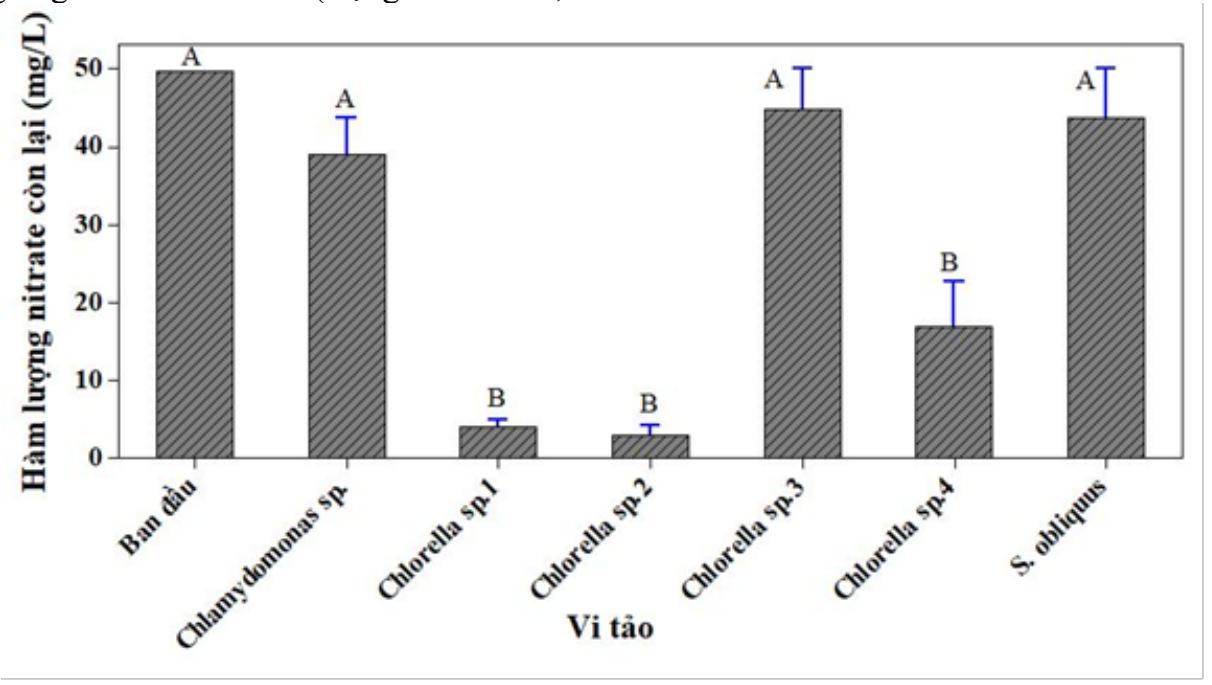

\section{Hình 5. Hàm lượng nitrate còn lại trong môi trường nuôi cấy 6 dòng vi tảo sau 14 ngày}

Các ký tư trên các cột giống nhau thể hiện hàm luợng nitrate trung bình khác biệt không ý nghĩa thống kê. Các thanh trên đầu cột là thanh sai sồ chuẩn.

Bên cạnh nitrate, orthophosphate $\mathrm{PO}_{4}{ }^{3-}$ cũng là một trong những nhân tố chính được tảo sử dụng trong quá trình chuyển hoá năng lượng để tổng hợp acid nucleic và các thành phần khác tạo thành sinh khối cho tảo. Giống như nitrate, phosphate cũng là yếu tố giới hạn sinh trưởng của tảo. Thiếu một trong các hợp chất này, tảo sinh trưởng và phát triển chậm tạo sinh khối rất thấp (Bougaran et al., 2010). Kết quả nghiên cứu cho thấy hàm lượng phosphate còn lại trong môi trường cấy tảo cũng giảm so với hàm lượng ban đầu cho vào môi trường (Hình 6). Điều này chứng tỏ các dòng vi tảo đã sử dụng phosphate trong quá trình biến dưỡng của chúng. Tuy nhiên, kết quả cũng cho thấy việc hấp thu phosphate cũng có hiệu quả khác nhau ở các dòng vi tảo. Trong đó, 2 dòng Chlorella sp. 1 và sp. 2 có khả năng hấp thu phosphate tốt hơn, khác biệt có ý nghĩa thổng kê so với các dòng còn lại. Nghiên cứu của Rasoul-Amini et al. (2014) cũng chứng minh khả năng xử lý phosphate trong nước thải cũng phụ thuộc vào dòng vi tảo.

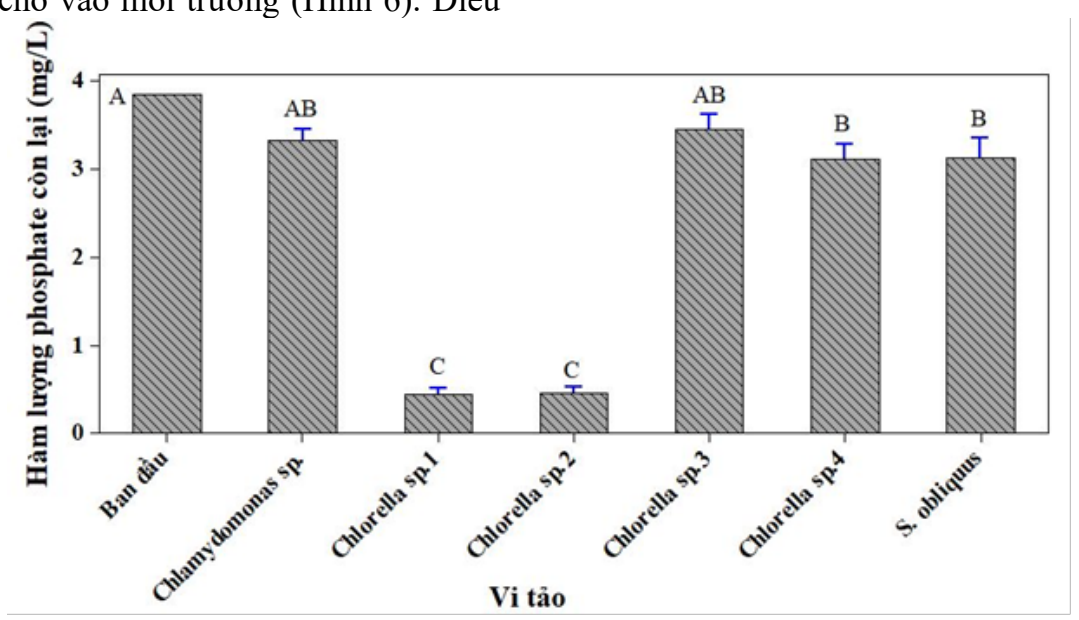

Hình 6. Hàm lượng phosphate còn lại trong môi trường nuôi cấy vi tảo sau 14 ngày

Các ký tư trên các cột giống nhau thể hiện hàm lương nitrate trung bình khác biệt không ý nghĩa thống kê. Các thanh trên đầu cột là thanh sai số chuẩn. 
Theo Lê Hoàng Việt (2003), hàm lượng nitrate và phosphate tổng số có trong nước thải sinh hoạt lần lượt nằm trong khoảng $20-85 \mathrm{mg} / \mathrm{L}$ và $4-15$ $\mathrm{mg} / \mathrm{L}$. Theo quy chuẩn kỹ thuật quốc gia về chất lượng nước mặt QCVN 08-MT:2015 do Bộ Tài Nguyên Môi Trường quy định, hàm lượng nitrate và phosphate cho phép lần lượt là $50 \mathrm{mg} / \mathrm{L}$ và $4-6$ $\mathrm{mg} / \mathrm{L}$. Do đó, đề tài chọn nồng độ ban đầu của nitrate là khoảng $50 \mathrm{mg} / \mathrm{L}$ và của phosphate xấp xỉ $4 \mathrm{mg} / \mathrm{L}$. Sau khi nuôi cấy tảo 14 ngày, Chlorella $\mathrm{sp} .1$ và sp.2 đã xử lý được trên $90 \%$ lượng nitrate và $88 \%$ lượng phosphate trong môi trường (Bảng 2). Như vậy, hai dòng vi tảo Chlorella $\mathrm{sp} .1$ và sp.2 này có khả năng xử lý nitrate và phosphate đạt quy chuẩn Việt Nam. Hơn nữa, kết quả này tương tự như kết quả nghiên cứu của Trần Chấn Bắc (2013) rằng cả nitrate và phosphate được xử lý hiệu quả (95\% với nitrate và 88,6\% đối với phosphate) khi Chlorella $\mathrm{sp}$. được nuôi trong nước ao cá tra. Do đó, kết quả này có thể đề nghị hai dòng tảo Chlorella $\mathrm{sp} .1$ và sp.2 phân lập từ nước thải sinh hoạt có tiềm năng trong việc xử lý nitrate và phosphate trong nước thải ở các nghiên cứu tiếp theo.

Bảng 2. Hiệu xuất xử lý nitrate và phosphate trong môi trường nuôi cấy 6 dòng vi tảo được phân lập từ nước thải

\begin{tabular}{|c|c|c|}
\hline Dòng vi tảo & Hiệu suất hấp thu nitrate (\%) & Hiệu suất hấp thu phosphate (\%) \\
\hline Chlamydomonas sp. & $21,3 \pm 16,5 \mathrm{~B}$ & $12,4 \pm 5,6 \quad$ B \\
\hline Chlorella sp.1 & $92,1 \pm 3,6 \quad \mathrm{~A}$ & $88,5 \pm 3,4$ \\
\hline Chlorella sp.2 & $94,2 \pm 4,8 \quad \mathrm{~A}$ & $88,1 \pm 2,9$ \\
\hline Chlorella sp. 3 & $16,5 \pm 9,6$ & $8,9 \pm 7,4$ \\
\hline Chlorella sp.4 & $66,1 \pm 20,3 \quad \mathrm{~A}$ & $18 \pm 7,4$ \\
\hline Scenedesmus obliquus & $18,6 \pm 16,5 \quad B$ & $17,5 \pm 10,4 \mathrm{~B}$ \\
\hline
\end{tabular}

Các ký tư giống nhau trong cùng 1 cột thể hiện hiệu suất trung bình khác biệt không ý nghĩa thống kê giũa các dòng vi tảo

Sinh khối các dòng vi tảo tăng lên sau 14 ngày nuôi cấy với giá trị $\mathrm{OD}_{650 \mathrm{~nm}}$ trung bình tăng đáng kể từ 0,075 đến 1,5 ; trong đó giá trị $\mathrm{OD}$ cao nhất đối với dòng vi tảo Chlorella sp.2 (Hình 7). Theo sau Chlorella sp.2, Chlorella sp.1 cũng đạt sinh khối cao $(\mathrm{OD}=1,2)$, khác biệt ý nghĩa thống kê so với sinh khối của các dòng tảo còn lại $(\mathrm{p}<0,001)$. Kết quả này cho thấy việc sử dụng nitrogen trong nitrate và phosphorus trong phosphate hiệu quả của 2 dòng Chlorella sp.1 và sp.2 đã giúp tăng sinh khối đáng kể của tảo. Nghiên cứu này đã cho kết quả tương tự nghiên cứu trước đây là tảo hấp thu tốt nitrate và phosphate sẽ chuyển hóa thành sinh khối cho chúng (Trần Chấn Bắc, 2013; Rasoul-Amini et al., 2014).

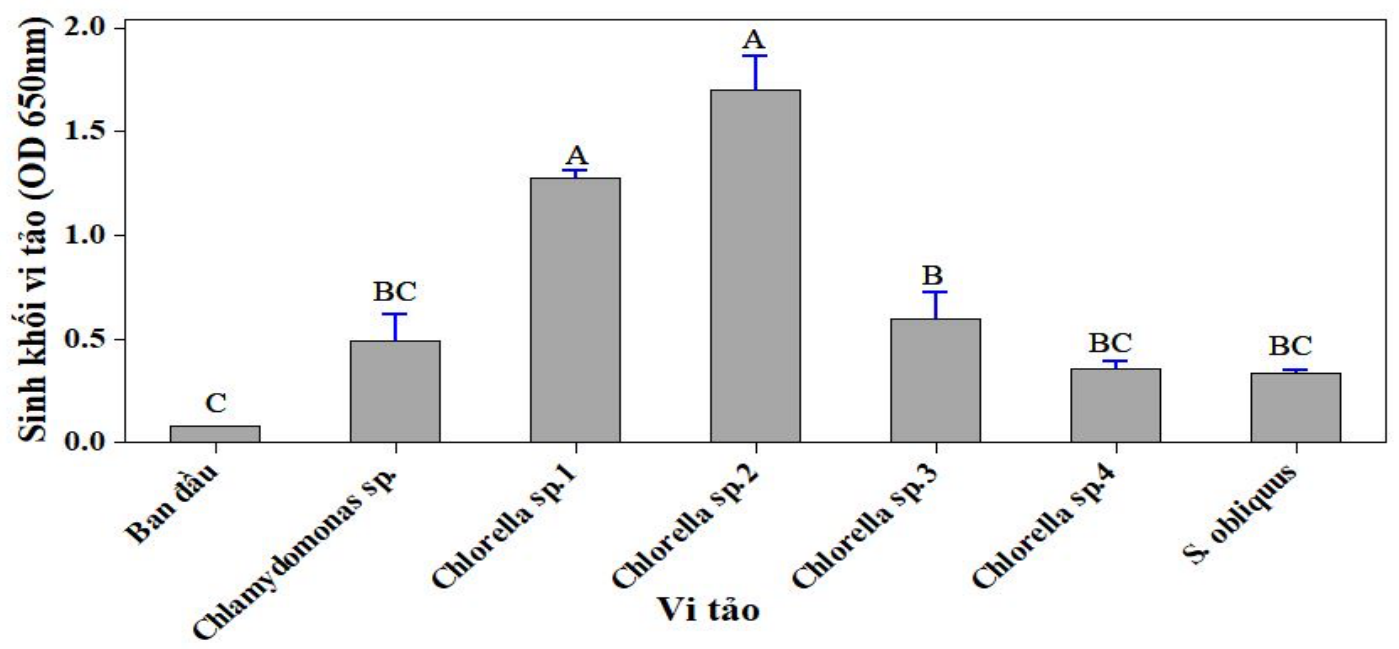

Hình 7. Giá trị OD của 6 dòng vi tảo sau 14 ngày nuôi cấy

\section{KẾT LUẬN}

Tóm lại, 12 dòng vi tảo được phân lập từ các nguồn nước thải sinh hoạt trên địa bàn quận Ninh
Kiều, thành phố Cần Thơ đã được định danh dựa vào đặc điểm hình thái. Sáu trong 12 dòng vi tảo được phân lập phát triển tốt trong môi trường WC lỏng. 
Trong đó, 2 dòng tảo cho hiệu suất xử lý cả nitrate (trên $90 \%$ ) và phosphate $(88 \%)$ tốt nhất là Chlorella sp.1 và sp.2. Kết quả nghiên cứu đề nghị sử dụng 2 dòng tảo tiềm năng này để xử lý nitrate và phosphate có trong nước thải sinh hoạt ở các thí nghiệm tiếp theo.

\section{LỜI CẢM TẠ}

Nhóm tác giả chân thành cảm ơn Trường Đại học Cần Thơ đã hỗ trợ tài chính cho nghiên cứu này.

\section{TÀI LIÊU THAM KHẢO}

Ahmad, F., Khan, A.U., \& Yasar, A. (2012). Uptake of nutrients from municipal wastewater and biodiesel production by mixed algae culture. Pakistan Journal Nutrition, 11(7), 648-652.

Bougaran, G., Bernard, O., \& Sciandra, A. (2010). Modeling continuous cultures of microalgae colimited by nitrogen and phosphorus. Journal of theoretical biology, 265(3), 443-454.

Bourrelly, P. \& Heim, R. (1966). Les algues d'eau douce : initiation à la systématique. Tome I, Les algues vertes. Paris : N. Boubée \& Cie., Ed., 151(1), 125-231.

Dineshkumar, R., Narendran, R., \& Sampathkumar, P. (2016). Cultivation of Spirulina platensis in different selective media. Indian Journal of Geo Marine Sciences, 45(12), 1749-1754.

Đặng Đình Kim (1999). Công nghệ sinh học vi tảo. Nhà xuất bản nông nghiệp

Graham, L.,E., \& Wilcox, L. W. (2000). Algae. Prentice Hall. Upper Saddle River. NJ 07458.

Guillard, R.R.L., \& Lorenzen, C.J. (1972). Yellowgreen algae with chlorophyllid C. Phycology. http://dx.doi.org/10.1111/j.15298817.1972.tb03995.x

Kim, J., Lingaraju, B.P., Rheaume, R., Lee, J.Y., \& Siddiqui, K.F. (2010). Removal of ammonia from wastewater effluent by Chlorella vulgaris. Tsinghua science and technology, 15(4), 391-396.

Lê Hoàng Việt. (2003). Kỹ thuật xử lý nước thải. Tủ sách Đại học Cần Tho.

McGaughy, K., Abu Hajer, A., Drabold, E., Bayless, D., \& Reza, M.T. (2019). Algal Remediation of Wastewater Produced from Hydrothermally Treated Septage. Sustainability, 11(12), 3454. https://doi.org/10.3390/su11123454.

Nguyễn Lân Dũng \& Nguyễn Hải Hà. (2006). Chương trình Vi sinh vật học, Vietsciences, Hà Nội.
Nguyễn Minh trí \& Trần Thị Bích Ngọc. (2015). Khả năng xử lý các tác nhân gây phú dưỡng môi trường nước của Bèo tai chuột (Salvinia cucullata). Hội nghị khoa học toàn quốc về sinh thái và tài nguyên thực vật lần thứ 6, 1749-1755.

Nguyễn Thị Kim Ngân \& Phạm Thị Mỹ Trâm. (2017). Nghiên cứu khả năng xử lý nước thải sinh hoạt của một số loài thực vật. Tạp chí Đại học Thủ Dầu Một, 35, 80-87.

Nguyễn Văn Tuyên. (2003). Đa dạng sinh học tảo trong thủy vực nội địa Việt Nam. Triển vọng và thứ thách. Nhà Xuất Bản Nông nghiệp.

Oyebamiji, O. O., Boeing, W. J., Holguin, F. O., Ilori, O., \& Amund, O. (2019). Green microalgae cultured in textile wastewater for biomass generation and biodetoxification of heavy metals and chromogenic substances. Bioresource Technology Reports, 7, 100-247.

Phạm Hoàng Hộ. (1967). Tảo học. Tủ sách khoa học. NXB BGD\&ĐT.

Rasoul-Amini, S., Montazeri-Najafabady, N., Shaker, S., Safari, A., Kazemi, A., Mousavi, P., \& Ghasemi, Y. (2014). Removal of nitrogen and phosphorus from wastewater using microalgae free cells in bath culture system. Biocatalysis and Agricultural Biotechnology, 3(2), 126-131.

Richmond, A. (2004). Handbook of microalgae culture: biotechnology and applied phycology. Black Well Science Ltd. Journal of Applied Phycology, 16, 159-160.

Taziki, M., Ahmadzadeh, H., Murry, M. A., \& Lyon, S. R. (2015). Nitrate and nitrite removal from wastewater using algae. Current Biotechnology, 4(4), 426-440.

Trần Chấn Bắc. (2013). Nghiên cứu hiệu quả kỹ thuật nuôi sinh khối tảo Chlorella sp. sử dụng nước thải từ ao nuôi cá tra. Tap chí Khoa hoc Truờng Đại Học Cần Tho, 28, 157-162.

Trần Chấn Bắc, Lê Thị Quyên Em, Phạm Hồng Nga, Nguyễn Xuân Lộc \& Nguyễn Minh Chơn. (2015). Sử dụng nước thải ao nuôi cá tra để nuôi sinh khối tảo Chlorella sp. Tạp chí Khoa học Truờng Đai Học Cần Tho, 39, 90-96.

Yang, S., Xu, J., Wang, Z. M., Bao, L. J., \& Zeng, E. Y. (2017). Cultivation of oleaginous microalgae for removal of nutrients and heavy metals from biogas digestates. Journal of cleaner production, 164, 793-803. 